\title{
Testing and evaluation of CFTRI dal mill for pigeonpea (Cajanus cajan)
}

VIJAY K. SINGH

Received : 01.03.2017; Revised : 01.07.2017; Accepted : 15.07.2017

Author for Correspondence :

VIJAY K. SINGH

Department of Processing and Food Engineering, College of Agricultural Engineering and Technology, C.C.S. Haryana Agricultural University, HISAR (HARYANA) INDIA

Email : vijurss@gmail.com
- ABSTRACT : This study covers the performance study of CFTRI dal mill using UPAS-120 variety of pigeonpea as untreated and treated grains. The machine performance was carried out in term of maximum grains input and output capacity, dehusking efficiency, milling efficiency, dal recovery, quality index. In dry milling method, it was found that the maximum grains input and output capacity were $83.77 \mathrm{~kg} / \mathrm{h}$ and $54.86 \mathrm{~kg} / \mathrm{h}$, respectively. The machine dehusking efficiency, milling efficiency, dal recovery, quality index, were $98.97 \%, 89.31 \%, 75.21 \%, 89.34 \%$, respectively while the pearled grains, broaken, powder, husk and undehusked grains were $4.35 \%, 2.90 \%, 5.68 \%$ 16.20 , and $0.03 \%$, respectively. The power consumption at no load and load conditions were 0.92 and $1.19 \mathrm{~kW} / \mathrm{h}$, respectively. Similarly in wet milling method, the maximum grains input and output capacity were $93.21 \mathrm{~kg} / \mathrm{h}$ and $63.79 \mathrm{~kg} / \mathrm{h}$, respectively. The machine dehusking efficiency, milling efficiency, dal recovery, quality index, were $98.90 \%, 92.83 \%, 75.21 \%, 92.93 \%$, respectively while the pearled grains, broaken, powder, husk and undehusked grains are $2.62 \%, 2.90 \%, 4.11 \% 16.23$, and $0.10 \%$, respectively. The power consumption at no load and load conditions are 0.92 and $1.03 \mathrm{~kW} /$ $\mathrm{h}$, respectively.

- KEY WORDS : Pigeonpea, Wet milling, Dry milling, Dal recovery, Quality index

- HOW TO CITE THIS PAPER : Singh, Vijay K. (2017). Testing and evaluation of CFTRI dal mill for pigeonpea (Cajanus cajan). Internat. J. Agric. Engg., 10(2) : 239-245, DOI: 10.15740/HAS/IJAE/ 10.2/239-245. 